\title{
CORRECTION
}

View Article Online

View Journal I View Issue

Check for updates

Cite this: RSC Adv., 2017, 7, 22340

DOI: $10.1039 / \mathrm{c} 7 \mathrm{ra90055d}$

www.rsc.org/advances

\section{Correction: Growth behavior of water dispersed MgAl layered double hydroxide nanosheets}

\author{
Xiujiang Pang, ${ }^{\star a}$ Li Chen, ${ }^{b}$ Yuan Liu, ${ }^{c}$ Mingjun Chi, ${ }^{b}$ Zaifeng Li $^{\star a}$ and Johann Plank ${ }^{d}$ \\ Correction for 'Growth behavior of water dispersed MgAl layered double hydroxide nanosheets' by Xiujiang \\ Pang et al., RSC Adv., 2017, 7, 14989-14997.
}

The authors regret that one of the discussed curves is missing from Fig. 11 of the original article. A revised version of Fig. 11, in which line a has now been added, is included herein.

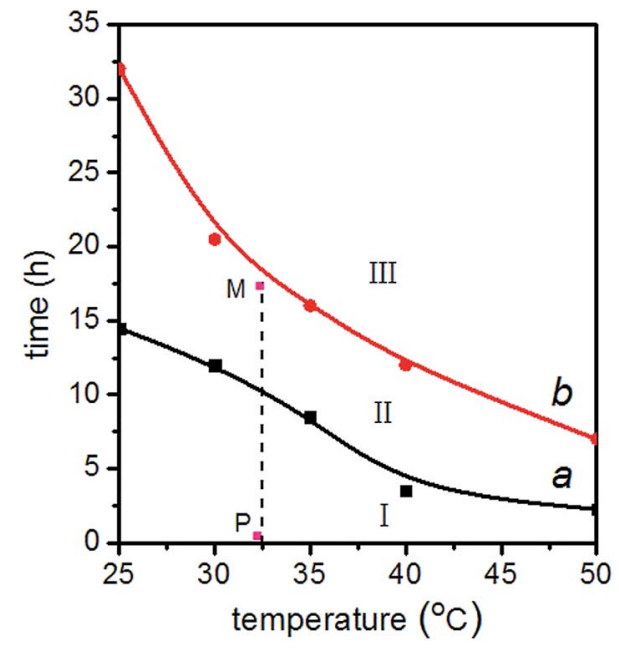

Fig. 11 The relationship between the temperature and time of the inflection points for the curves of $T-t$ and $\eta-t$. (I) Nanosheets cluster, (II) nanosheets cluster and dispersed nanosheets, and (III) stacked nanosheets.

The Royal Society of Chemistry apologises for these errors and any consequent inconvenience to authors and readers.

${ }^{a}$ State Key Laboratory Base of Eco-chemical Engineering, College of Chemistry and Molecular Engineering, Qingdao University of Science and Technology, Qingdao 266042, P. R. China. E-mail: xiujiangpang@qust.edu.cn

${ }^{b}$ Key Laboratory of Rubber \& Plastics, Ministry of Education, Shandong Provincial Key Laboratory of Rubber and Plastics, Qingdao University of Science and Technology, Qingdao 266042, P. R. China

${ }^{\prime}$ College of Petroleum Engineering, China University of Petroleum (East China), Qingdao 266042, P. R. China

${ }^{d}$ Technische Universität München, Chair for Construction Chemicals, Garching 85747, Germany 